University of Nebraska - Lincoln

DigitalCommons@University of Nebraska - Lincoln

USDA National Wildlife Research Center - Staff Publications
U.S. Department of Agriculture: Animal and Plant Health Inspection Service

2015

\title{
Effect of travel distance, home range, and bait on the management of small Indian mongooses, Herpestes auropunctatus
}

William C. Pitt

U.S. Department of Agriculture, Animal and Plant Health Inspection Service, Wildlife Services, National Wildlife Research Center, Hawaii Field Station, Hilo, HI, pittw@si.edu

Robert T. Sugihara

U.S. Department of Agriculture, Animal and Plant Health Inspection Service, Wildlife Services, National Wildlife Research Center, Hawaii Field Station, Hilo, HI

Are R. Berentsen

U.S. Department of Agriculture, Animal and Plant Health Inspection Service, Wildlife Services, National Wildlife Research Center, Fort Collins, $C O$

Follow this and additional works at: https://digitalcommons.unl.edu/icwdm_usdanwrc

Part of the Life Sciences Commons

Pitt, William C.; Sugihara, Robert T.; and Berentsen, Are R., "Effect of travel distance, home range, and bait on the management of small Indian mongooses, Herpestes auropunctatus" (2015). USDA National Wildlife Research Center - Staff Publications. 1714.

https://digitalcommons.unl.edu/icwdm_usdanwrc/1714

This Article is brought to you for free and open access by the U.S. Department of Agriculture: Animal and Plant Health Inspection Service at DigitalCommons@University of Nebraska - Lincoln. It has been accepted for inclusion in USDA National Wildlife Research Center - Staff Publications by an authorized administrator of DigitalCommons@University of Nebraska - Lincoln. 


\title{
Effect of travel distance, home range, and bait on the management of small Indian mongooses, Herpestes auropunctatus
}

\author{
William C. Pitt $\cdot$ Robert T. Sugihara • \\ Are R. Berentsen
}

Received: 29 May 2014/ Accepted: 17 December 2014/Published online: 10 January 2015

(C) Springer International Publishing Switzerland (outside the USA) 2015

\begin{abstract}
Selection of preferred baits to attract mongooses to traps and other control devices is paramount in the effective management and control of this invasive predatory mammal. We examined the attractiveness of selected food items as baits to free-ranging mongooses in field trials at two different habitats on the island of Hawaii. We utilized radio telemetry to calculate mongoose home range and population density estimates. We implanted microchips to remotely identify and record visitations by mongooses to the candidate baits and investigated bait visitation rates, bait attraction distances, and bait discovery times. Mongooses in this study foraged over a wide area and readily investigated the various novel food baits, with fish, beef and egg-baited stations eliciting higher first and revisits over multiple days. We radio collared 34 mongooses. Overall mean home range estimates were
\end{abstract}

W. C. Pitt $(\bowtie) \cdot$ R. T. Sugihara

U.S. Department of Agriculture, Animal and Plant Health Inspection Service, Wildlife Services, National Wildlife Research Center, Hawaii Field Station, Hilo, HI 96720, USA

e-mail: pittw@si.edu

Present Address:

W. C. Pitt

Smithsonian Conservation Biology Institute, National

Zoological Park, Front Royal, VA 22630, USA

A. R. Berentsen

U.S. Department of Agriculture, Animal and Plant Health Inspection Service, Wildlife Services, National Wildlife Research Center, Fort Collins, CO, USA
21.9 and 28.8 ha and did not differ between the two study sites $(\mathrm{F}=2.12, p=0.156)$, although overall male mongooses had larger home ranges than females $(\mathrm{F}=22.92, \mathrm{df}=1, p<0.0001)$. Extensive overlapping home ranges were recorded among individual mongooses, regardless of gender. Male mongooses were attracted from a greater distance to selected baits as compared to females ( $\mathrm{F}=15.80, \mathrm{df}=1, p=0.0004)$ although females visited more bait stations than males at each site $(\mathrm{F}=11.26, \mathrm{df}=1, p=0.002$ and $\mathrm{F}=6.90$, df $=1, p=0.017)$. Baits were usually discovered within 24-30 h of exposure. Based on time to first bait discovery, no differences were found among percent of food stations visited among bait types at either site $(\mathrm{F}=0.93, \mathrm{df}=4$, $p=0.463$ and $\mathrm{F}=0.40, \mathrm{df}=3, p=0.756$ ). The results of this study provide insights on mongoose foraging ecology in Hawaii and the attractiveness of food baits used in developing effective control strategies in detecting and trapping mongooses in newly established areas as well as reducing or eradicating populations in native species habitat impacted by mongooses.

Keywords Bait attractiveness - Control - Foraging distance $\cdot$ Hawaii $\cdot$ Management

\section{Introduction}

The small Indian mongoose [Herpestes javanicus (=auropunctatus)] is an opportunistic omnivore native to parts of South Asia, Southeast Asia, and parts of the 
Middle East (Nellis 1989). In the late 1800s and early 1900s, small Indian mongooses were introduced to sugarcane growing islands in several parts of the world, including Puerto Rico, the Virgin Islands, and the Hawaiian Islands, with the hope of controlling rodent damage (Espeut 1882; Nellis and Everard 1983; Hoagland et al. 1989). Barun's (2011) review noted intentional worldwide introductions include 64 islands and at least one continental mainland area for controlling rats and venemous snakes. Like most attempts at biological control of vertebrate pests, mongoose introductions have caused substantial threats to or extinctions of native bird, amphibian, reptile and mammal species (Seaman and Randall 1962; Nellis and Small 1983; Roy et al. 2002; Yamada 2002; Watari et al. 2008). In some regions they have also become sylvatic reservoirs of rabies, leptospirosis, or canine distemper (Blanton et al. 2006). Most releases occurred in sugarcane growing areas that, in Hawaii, dominated agricultural land-use on the larger islands. Mongooses have very diverse diets (Gorman 1975; Baldwin et al. 1952) and have been found to be opportunistic, non-selective feeders (Linhart et al. 1993; Creekmore et al. 1994; Vilella 1998). Mongooses certainly eat rats, but they have clearly been ineffective in exerting sufficient pressure on rodent populations to alter damage patterns (Baldwin et al. 1952; Seaman 1952; Gorman 1975). Much of this failure can be attributed to the diurnal and terrestrial nature of mongooses, as opposed to the largely nocturnal and terrestrial or arboreal nature of rats. Such differing spatial use limits the potential for interaction between the two species.

In Hawaii, mongooses are serious predators of native avian species in forest, wetland, and upland habitats (Bryan 1908; Baker and Russell 1979; Banko 1982, 1992; Giffin 1983; Stone et al. 1994-1995; Hodges and Nagata 2001; Eijzenga 2004), and have similar impacts in other areas of the world where they have been introduced (Pimentel 1955; Seaman and Randall 1962; Nellis and Everard 1983; Hoagland et al. 1989; Roy et al. 2002; Yamada and Sugimura 2004; Barun 2011). In the Hawaiian Islands the eggs and nestlings of ground-nesting birds are especially vulnerable to these invasive mammals which occupy diverse habitats on most of the major islands. A number of Hawaiian birds, including the endangered Hawaiian goose (Branta sandvicensis), crow (Corvus hawaiiensis), wetland-inhabiting Hawaiian duck
(Anas wyvilliana), coot (Fulica americana alai), stilt (Himantopus mexicanus), and gallinule (Gallinula galeata sandvicensis), as well as the colonial, burrownesting dark-rumped petrel (Pterodroma sandwichensis) and Newell's shearwater (Puffinus newelli), are threatened by mongoose predation, presenting a serious concern to resource managers in Hawaii (Anonymous 2010).

Trapping and rodenticides have been used in attempts to reduce high density mongoose populations in native bird nesting habitats (Stone and Keith 1987; Keith et al. 1990; Smith et al. 2000). However, these methods have been less successful in areas with low mongoose density or high alternate prey density and more efficient methods are needed before larger scale control or eradication is feasible (Barun et al. 2011). In addition, the potential for accidental introductions on mongoose-free islands in the Hawaiian and Pacific Islands highlights the need for improved index/capture techniques utilizing traps, baits or attractants. Research by Pitt and Sugihara (2008) found that certain food baits elicit higher visitation rates and capture success of mongooses in Hawaii than synthetic attractants and suggested strategic bait application may attract mongooses from outside their normal activity range.

Our objectives were to (1) use radio telemetry to estimate local movement patterns, population density and home ranges of mongooses and (2) use travel distance and time to locate baits as a means to evaluate five candidate food baits. We hope to apply this information to address questions of eradication and control strategies related to stimulation of extraterritorial movements. That is, can a food source draw an individual mongoose out of its movement patterns and serve as a technique for area-wide eradication?

\section{Methods}

Study site

This study was conducted on two sites near Hilo, Hawaii $\left(19^{\circ} 42^{\prime} \mathrm{N}, 155^{\circ} 2^{\prime} \mathrm{W}\right)$.

The first site (Kaiwiki) consisted of approximately 41 ha of an 80-ha commercial eucalyptus (Eucalyptus grandis) forest on former sugarcane (Saccharum officinarum L.) cultivated lands. Eucalyptus trees were 7-8 years old and planted at $2.5-3.0 \mathrm{~m}$ spacing 
at a density of approximately 1,600 trees/ha. Terrain was gently sloping and consisted primarily of Hilo clay-loam soil. Vegetation included a variety of perennial grasses, including California grass (Brachiaria mutica), assorted crabgrasses (Digitaria spp.), and Guinea grass (Panicum maximum). Ground ferns and volunteer sugar cane (Saccharum officinarum) were also common. Numerous narrow interior access roads dissected the study area.

At Kaiwiki, we established 12 parallel, 300-m long transects, each approximately $100-150 \mathrm{~m}$ apart (Fig. 1). Transects ran perpendicularly from a central access road towards drainage gulches adjacent to the site. Ten food bait stations were placed at $25-\mathrm{m}$ intervals along each transect for a total of 120 stations. These stations were used as trapping locations and as reference locations for locating mongooses and evaluating station visitations. A single Tomahawk ${ }^{\circledR}$ live trap was placed at every other station (50 m spacing) along each transect for a total of 60 traps.

The second site was approximately 24 ha of the 100-ha Keaukaha Military Reservation (KMR) located near the Hilo International Airport. Terrain is composed of a largely rocky lava substrate covered with a thin layer of mostly organic compost supporting non-native vegetation. The understory was dominated by molasses grass (Melinis minutiflora), broomsedge (Andropogon spp.), rattlepod (Crotalaria spectabilis), and various ferns (Nephrolepis spp. Common trees included gunpowder tree (Trema orientalis), ohia (Metrosideros polymorpha), and strawberry guava (Psidium cattleianum).

We delineated four parallel 600-700-m long transects, spaced 100-150 m apart. Six or seven trapping stations were established along each transect with $100 \mathrm{~m}$-spacing between stations (Fig. 2). Two Tomahawk $^{\circledR}$ live traps were placed 5-6 m apart at each station and at a midpoint location along each of the transect cross trails for a total of 70 traps. Station locations were recorded using a handheld global positioning system at both sites.

\section{Capture and handling}

Mongooses were live-captured using cage traps (Tomahawk $\left.{ }^{\circledR}\right)$ baited with fresh coconut chunks $\left(3 \mathrm{~cm}^{2}\right)$ routinely used to capture mongooses in Hawaii. Trap sites were pre-baited with shredded coconut for 3 days in order to increase trapping success. Traps were checked twice daily (0800-1000 h and 1400-1600 h) Monday-Friday until no unmarked mongooses were captured for three consecutive days. Captured mongooses were transported in cage to a central processing area typically at the head of transects or at access road intersections within the study site. The cage with the mongoose was placed in a portable induction chamber primed with Isoflurane ${ }^{\circledR}$ anesthesia. Once sedated, the mongoose was removed from the chamber and cage.
Fig. 1 Kaiwiki study site, showing core trapping grid with stations spaced $25 \mathrm{~m}$ apart. Traps placed at every other station at $50 \mathrm{~m}$ spacing. Area was bound on 3 sides by deep drainage gulch

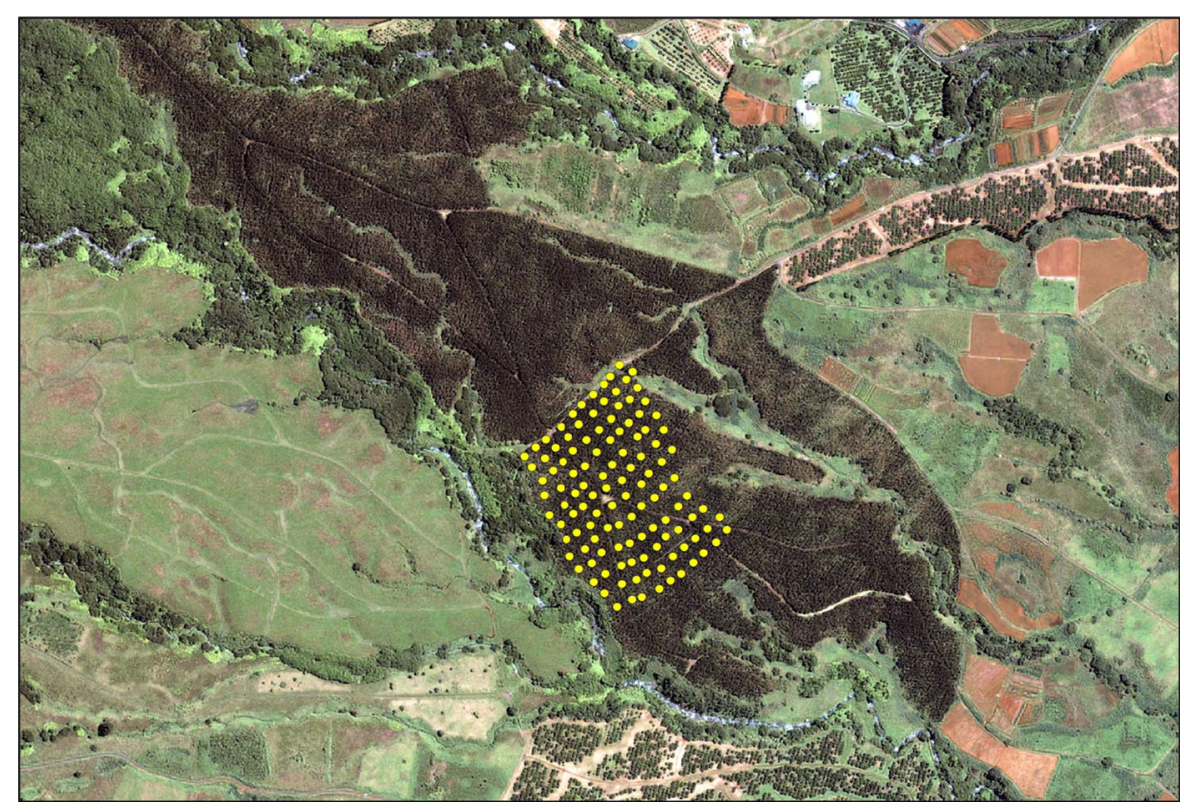


Fig. 2 KMR Study Site, showing trapping grid with stations spaced approximately $100 \mathrm{~m}$ apart. Cross transect stations on alternate transects placed at $50 \mathrm{~m}$ spacing

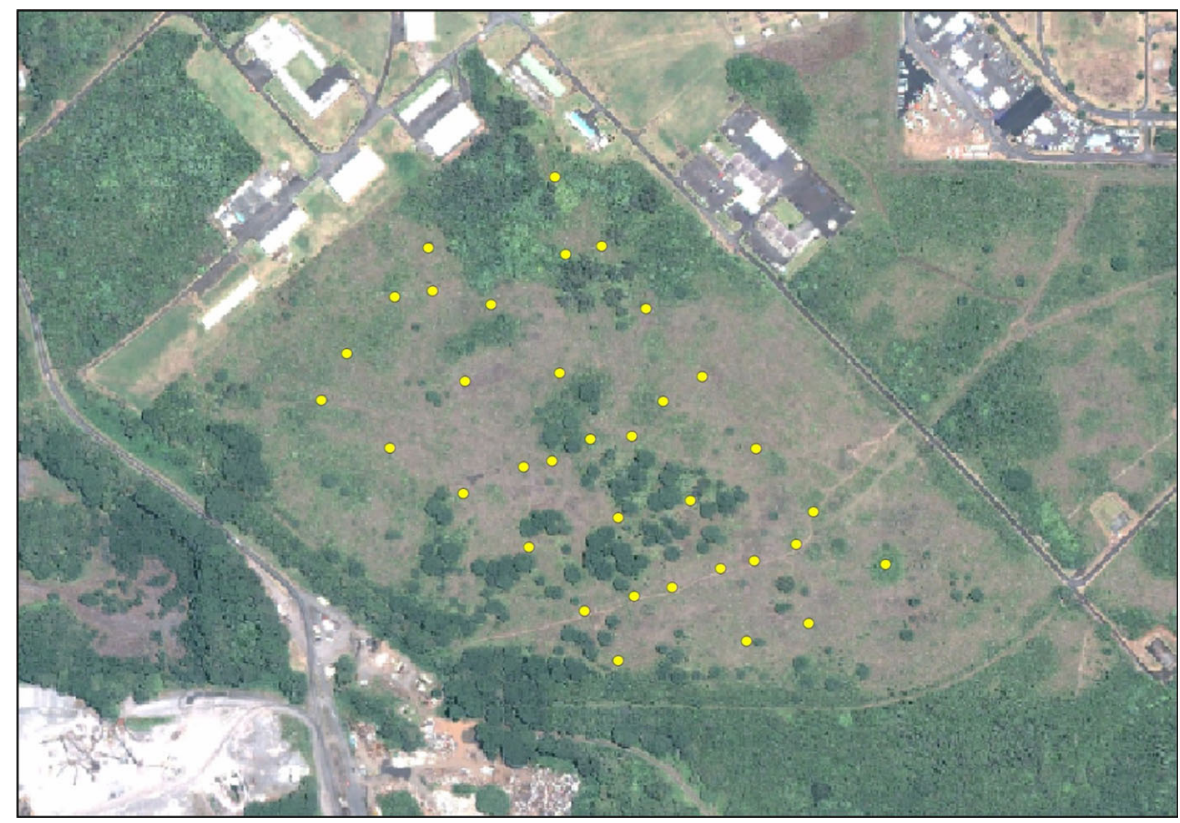

An AVID $^{\circledR}$ (AVID ID Systems, Norcross, CA, USA) injectable microchip (PIT- passive integrated transponder) was implanted subcutaneously between the shoulder blades and another chip injected in the dorsal rump area to uniquely identify each mongoose. Selected individuals of each gender and size class were also fitted with radio-transmitters (Advanced Telemetry Systems ${ }^{\circledR}$, Isanti, MN, USA). Each mongoose was monitored until recovery from anesthesia and released at the point of capture. Non-target animals were released.

Radio tracking and home range estimates

At the Kaiwiki site, we used portable telemetry receivers (Advanced Telemetry Systems ${ }^{\circledR}$ ) and handheld 3-element Yagi antennas (Wildlife Materials ${ }^{\circledR}$, Murphysboro, IL, USA) to obtain 2-3 bearings from selected GPS-referenced locations yielding the strongest triangulation or biangulation signal to estimate each radio-collared mongoose's location to the nearest trapping station placed at $25-\mathrm{m}$ intervals within the study site. At KMR, we established three fixed, permanent radio-telemetry tracking stations (thick overstory canopy, deep drainage gulches, and limited line-of-sight terrain features precluded accurate use of permanent triangulation tracking stations at Kaiwiki) to estimate location error. Each "null-peak" receiving station consisted of dual 5-element Yagi antennas mounted on a 4-m extended boom attached to a stationary tripod. A compass rose and telemetry receiver mated to the antenna system were used to determine the azimuth of the target transmitter. Two or three operators simultaneously (within 30-60 s) determined a mongoose's location by triangulation or biangulation. Only locations with good convergence (as close as $90^{\circ}$ ) were used. We used the "maximum likelihood estimator" in the LOAS $^{\circledR}$ software to estimate locations of radio-collared mongooses. In cases where only two bearings were obtained, we used the "best biangulation" function. Locations were entered into $\operatorname{ArcMap}^{\circledR}$ v 9.x (ESRI ${ }^{\circledR}$, Redlands, CA, USA). Home ranges were estimated using minimum convex polygons (MCP).

We located mongooses daily at both sites from Monday to Friday for 3-4 weeks to determine their central area of use (core foraging area) and movement patterns prior to placement of test food baits. For each monitoring session for each mongoose, we recorded transmitter frequency, signal strength, animal location (nearest grid station or triangulation azimuth), activity (movement as determined by transmitter signal fluctuation), date, time, and local weather conditions (rain, wind, cloud cover). Signals deemed stationary for two consecutive days were tracked with handheld receiver units to determine their fate (detached collar, mortality). Animals were sometimes located outside of the core areas and their positions were determined, 
recorded, and flagged using handheld receiving units for later recording in our global positioning system (GPS) database.

Prior to each monitoring session, stations were calibrated using fixed beacon transmitters placed within the study area to optimize location accuracy. In addition, we conducted single blind tests two to three times per week to determine the estimated location error. Two to three test transmitters were hidden by a third party at different locations and azimuths recorded by each operator from their respective triangulation station.

\section{Test baits}

Five food baits palatable to mongooses (Pitt and Sugihara 2008) were evaluated: (1) fish- frozen whole mackerel, thawed and sliced into $2.5 \times 1.25-\mathrm{cm}$ pieces; (2) egg- fresh, whole, small commercial chicken egg; (3) processed frankfurters (hot dogs), made of beef and pork, cut into 1.25 -cm wide pieces; (4) coconut- fresh whole coconut cut into $2.5-\mathrm{cm}$ cubes; and (5) beef- meat market scrap beef trimmings cut into $2.5-3.0 \mathrm{~cm}^{2}$ pieces. At the KMR site hot dogs were excluded from further evaluation after the first session because invertebrates, particularly ants ( $\mathrm{Mo}$ nomorium spp. Pheidole spp.), earwigs (Chelisoches morio Fabr.), cockroaches (Blatella germanica, Periplaneta spp.), and slugs (Veronicella cubensis, Deroceras spp.), rapidly reduced the quantity and quality of the bait.

The fresh food baits were individually placed in sealed mesh pouches $(10 \times 20 \mathrm{~cm})$ constructed from $10-\mathrm{mm}$ mesh plastic hardware cloth. The open end of a pouch was closed with nylon twine and the pouch was secured (zip-ties) to the floor of an open-ended 12.7$\mathrm{cm}$ diameter $\times 38.1-\mathrm{cm}$ long Quonset ${ }^{\circledR}$ hut-shaped bait station constructed from waxed white signboard paper.

\section{Monitoring bait station visits}

We attached a battery-powered AVID $^{\circledR}$ microchip reader/data logger to each bait station to automatically detect and record marked mongoose visits. A laptop computer was used to program the data logger and activate and download mongoose visitation data. The bait station number and bait type, mongoose AVID $^{\circledR}$ microchip number, and the date and time of each visitation were recorded and stored for later data retrieval and analysis.

Each bait type was tested separately during 1-3 day bait exposure periods per bait type. On exposure day 1 the locations of all radio-collared mongooses were first determined by triangulation. Subsequently, five to ten stations baited with the test food were strategically placed within the study site and perimeter areas, usually at locations $>500 \mathrm{~m}$ away from where the mongooses were detected. Stations were spaced 50-100 m apart on three to four linear transects each $300-500 \mathrm{~m}$ in length. This pattern was based on the size of mongoose home range and daily travel distance determined during the pre-bait exposure monitoring period. The tag readers and dataloggers were activated and tested prior to placement in the field.

On each of the next bait exposure days operators first determined the location of each radio-collared mongoose. Each bait station was then checked, the data logger queried and mongoose visitation data downloaded to a laptop computer. Missing, disturbed, or partly eaten (non-targets, parasites) bait was replaced with whole bait stored under ambient conditions at the field station. The attractiveness of test baits to mongooses was determined based on: (1) distance traveled to baits; (2) elapsed time to find bait; and (3) frequency of visitations to a particular test bait.

\section{Data analysis}

We assessed the spatial (foraging distance) and temporal (time and frequency of visitation) responses of marked mongooses to the food baits and monitored bait attractiveness over a 3-day bait exposure period. Data on mongoose visitations to bait stations were also examined for clues on mongoose foraging ecology (solitary or group foraging behavior, peak foraging time of day, effect of previous exposure on subsequent visitation, and potential development of site fidelity near known food sources.

Differences in mongoose movement patterns (daily travel distance) and area of use (home range) by gender, size class, and location were examined using multivariate SAS $^{\circledR}$ ANOVA tests - SAS GLM ${ }^{\circledR}$ (home range $=$ sitelsex). Daily travel distances pre-and post-bait exposure were also compared. Separate analyses were done for the Kaiwiki and KMR study sites. Similar appropriate statistical tests were used to determine whether any of the test food baits 
were more attractive (distance and elapsed time to bait) to mongooses than the others. If significant differences were found, adjustments for multiple comparisons were made. Statistical significance was given at $p<0.05$. Population density estimates were performed in Program CAPTURE using the model containing time and behavior $\left(\mathrm{M}_{t b}\right.$; White et al. 1982).

\section{Results}

Mongoose captures

\section{Kaiwiki}

At Kaiwiki 26 mongooses (18 females, 8 males) were captured and marked during a 3-week trapping period (03 March 2006-26 March 2006). Mean body weights (range) were $719.5 \mathrm{~g}$ (440-985 g) for males and $409.4 \mathrm{~g} \mathrm{(235-590} \mathrm{g)} \mathrm{for} \mathrm{females.} \mathrm{While} \mathrm{all} \mathrm{but} \mathrm{one}$ of the male mongooses was of adult size class, eight females had imperforate vaginas, suggesting a relatively high proportion of dispersing unmated (subadult) female mongooses.

Radio transmitters were attached to six female and seven male mongooses prior to release. Fifteen (58\%) mongooses were recaptured at least once on subsequent trapping days with two individuals re-trapped five and seven times respectively. Most recaptures occurred within $100 \mathrm{~m}$ from their initial capture trap location. There were no new captures recorded in the 60 live traps within the study site during the last 3 days of the trapping session. Mongooses were trapped on all 12 transects with the majority of captures occurring at stations located within $100 \mathrm{~m}$ from the adjacent drainage gulches near the head and end of each transect. Estimated population density is $0.72 / \mathrm{ha}$ (95\% CI 0.65-1.94/ha).

\section{Keaukaha Military Reservation}

At KMR 41 mongooses (33 females, 8 males) were captured and marked over a 4-week trapping period (16 October 2007-15 November 2007). Mean body weights (range) for males were $645 \mathrm{~g} \mathrm{(490-790} \mathrm{g)} \mathrm{and}$

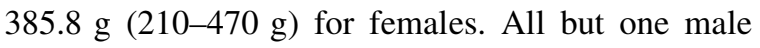
mongoose was of adult age class and seven females were classified as sub adults based on body size and imperforate vaginas. Twenty one (8 males, 13 females) of the captured mongooses at KMR were fitted with radio collars. Mongooses were trapped at 19 of the 35 stations with captures occurring fairly equally throughout the trapping grid. $59 \%$ (24 of 41) of mongooses were recaptured at least once with nine mongooses re-trapped twice during the initial trapping/marking period. Estimated population density is $3.92 / \mathrm{ha}$ (95\% CI $1.88-31.4 / \mathrm{ha}$ ).

Mongoose locations, daily foraging distance and home range

\section{Overall results}

We obtained 18-70 fixes per mongoose. Minimum convex polygon home range estimates were calculated from all locations obtained for each mongoose throughout the study period. Average mongoose home range estimates (minimum convex polygon) and consecutive daily (24-30 h) travel distances by study site and gender are summarized in Table 1. Daily travel distance summaries shown in Table 1 are for the pre-bait exposure period. Overall daily travel distances were 209.4 and $216.8 \mathrm{~m}$ for Kaiwiki and KMR, respectively, and did not differ between sites $(\mathrm{F}=0.13$, $\mathrm{df}=1, p=0.725)$. Males travelled farther than females $(\mathrm{F}=14.85$, $\mathrm{df}=1, p=0.006)$. Overall individual mongoose home ranges based on estimated locations obtained over the 99-day tracking period ranged from 6.0 to 70.2 ha. Overall mean home range estimates were 21.9 and 28.8 ha for Kaiwiki and $\mathrm{KMR}$, respectively, and did not differ $(\mathrm{F}=2.12$, $p=0.156)$. Male mongooses had larger home ranges than females $(\mathrm{F}=19.37$, df $=1, p<0.0001)$.

\section{Kaiwiki}

The general locations (nearest station within $25 \mathrm{~m}$ ) of all radio-collared mongooses $(n=13)$ were determined at least once daily (except weekends and holidays) during the 3-week trapping and subsequent 2.5 month bait exposure periods. All mongooses were active (moving) during the daylight tracking sessions (0800-1600 h) and the few attempts to locate refugia sites at night were unsuccessful due to the limited transmitter range and poor signal directionality of animals presumably hunkered down in sheltered belowground cavity den locations. 
Table 1 Home ranges and daily travel distances of male and female mongooses at two study sites near Hilo, Hawaii

\begin{tabular}{|c|c|c|c|c|c|c|c|c|}
\hline \multirow[t]{2}{*}{ Location } & \multicolumn{4}{|c|}{ Home range (MCP) } & \multicolumn{4}{|c|}{ Travel distance } \\
\hline & $\mathrm{N}$ & $\begin{array}{l}\text { Mean \# } \\
\text { tracking } \\
\text { days }\end{array}$ & $\begin{array}{l}\text { Mean } \pm \text { SE } \\
\text { (ha) }\end{array}$ & Range & $\mathrm{N}$ & $\begin{array}{l}\text { Mean \# } \\
\text { tracking } \\
\text { days }\end{array}$ & $\begin{array}{l}\text { Mean } \pm \mathrm{SE} \\
(\mathrm{m})\end{array}$ & Range \\
\hline \multicolumn{9}{|l|}{ Kaiwiki } \\
\hline M & 7 & 52.4 & $28.7 \pm 6.1$ & $7.6-51.0$ & 7 & 21.4 & $245.2 \pm 36.2$ & $0.0-1,208.1$ \\
\hline $\mathrm{F}$ & 6 & 83.3 & $14.0 \pm 3.3$ & $6.0-30.0$ & 6 & 37.6 & $167.6 \pm 19.1$ & $0.0-658.5$ \\
\hline \multicolumn{9}{|c|}{ Keaukaha Military Reservation } \\
\hline M & 8 & 115.7 & $45.7 \pm 7.2$ & $11.2-70.2$ & 8 & 24.9 & $268.9 \pm 22.3$ & $0.0-862.5$ \\
\hline $\mathrm{F}$ & 13 & 127.8 & $18.4 \pm 1.8$ & $8.6-30.0$ & 13 & 29.7 & $184.7 \pm 7.8$ & $0.0-560.3$ \\
\hline
\end{tabular}

The VHF signals from three mongooses were not detectable after 29, 32, and 38 days respectively, although the animals were detected at bait stations for an additional 23-40 days. Four mongooses were found dead: one of unknown causes and three were inadvertently trapped and killed on an adjacent poultry farm. These animals were monitored for 61-66 days before their premature demise.

Male and female mongooses had similar home ranges $(\mathrm{F}=4.06, \mathrm{df}=1, p=0.069)$. There were extensive overlaps in home ranges among individual mongooses and between males and females. Male and female mongooses foraged similar distances within consecutive days $(\mathrm{F}=3.24, \mathrm{df}=1, p=0.099)$. One male mongoose was located approximately $1,200 \mathrm{~m}$ from its previous day's location; the largest daily distance traversed by a female was $658 \mathrm{~m}$. Daily travel distances were similar $(\mathrm{F}=0.01, \mathrm{df}=1, p=0.910)$ during the period before and after food baits were deployed in the field.

During the pre-bait exposure period several radiocollared mongooses were unusually co-located near one location for a period of 14 days at the Kaiwiki site. The decomposing remains (skin, skeleton, meat) of an adult feral pig (Sus scrofa) discarded by a weekend hunter at the northern edge of the study site was discovered as the source of the mass congregation. On one occasion, six different radio-tagged mongooses were simultaneously detected at or near the pig carcass, although there could have been additional uncollared but microchipped mongooses present. No mongooses were recorded at the carcass site after 14 days from discovery of the pig carcass.

This unplanned "bait" appears to be highly attractive to mongooses. Based on their last locations prior to carcass disposal (likely Saturday or Sunday) and discovery (1.5-2 days after disposal), six mongooses traversed an average of $354.2 \mathrm{~m}$ (males $=315.6 \mathrm{~m}$, females $=200.2 \mathrm{~m}$ ) to the rotting carcass. Both male $(n=2)$ and female $(n=4)$ mongooses were attracted to the carcass. Limited sample sizes precluded any statistical inferences on carcass attractiveness by gender.

\section{Keaukaha Military Reservation}

At the KMR study site we determined the mean location error of the triangulations was $12.58 \mathrm{~m}$ $(\mathrm{SE}=0.52 \mathrm{~m}$, range $=1.02-22.51 \mathrm{~m})$, based on 119 single blind placements of test transmitters and triangulations from the three fixed stations by five operators conducted before or during the course of field study.

All 21 radio-collared mongooses were tracked daily (except weekends and holidays) when observers were in the field over the 4.5 month study period at the KMR site. All but two of the female mongooses remained within the core trapping grid area; two female mongooses ventured to an adjacent heavilyvegetated patch of Metrosideros and various exotic trees and shrubs to the east of the core area. Male individuals ranged freely (up to $900 \mathrm{~m}$ ) out into adjacent grassland and public areas.

The radio signals from three mongooses were not detectable after 55, 71, and 80 days respectively, although one of the mongooses visited bait stations until the end of the study period. The rest of the transmitters were operational until the end of the 134-day tracking period. A single radio-tagged mongoose was recovered dead near the completion of the 
study outside a maintenance shed located on the perimeter of the study area. No visible wounds were found and the reason for its death could not be determined.

Over the entire study period individual mongoose home ranges ranged from 8.6 to 70.2 ha. Male mongoose home ranges were larger than females $(\mathrm{F}=20.33, \mathrm{df}=1, p=0.0002)$ (Table 1$)$. Similarly to the Kaiwiki site, there were extensive overlaps in home ranges among individual mongooses and between males and females. Mean pre-bait exposure consecutive daily (24-30 h) travel distances by gender is summarized in Table 1. Daily foraging distances were greater for males than females $(\mathrm{F}=17.85$, $\mathrm{df}=1, p<0.0005)$. Overall daily travel distances were greater $(\mathrm{F}=12.85, \mathrm{df}=1, p=0.0004)$ during the bait exposure period $($ mean $=242.2 \mathrm{~m}$, range $=0.0-862.5 \mathrm{~m}$ ) as compared to the pre-exposure period $($ mean $=195.5 \mathrm{~m}$, range $=4.7-624.1 \mathrm{~m})$.

One week prior to the end of the tracking session a dead feral pig carcass was discovered just outside of the core KMR study site. Similarly to the Kaiwiki site, the bloated carcass was visited by four radio-collared mongooses. On the previous day a single male and female mongoose were located 388.0 and $213.0 \mathrm{~m}$ respectively from the pig carcass (Table 2 ). Consecutive day's locations were unavailable for the other two mongooses attracted to the carcass.

\section{Bait station visitations}

\section{Kaiwiki}

A total of 97 separate mongoose visits (detections at bait stations) were recorded during 202 bait station exposure days by 18 tagged mongooses at Kaiwiki over 16 1-3-day exposure sessions (04 April 2006-26 May 2006). Mongooses were detected at the baits between $0600-1800 \mathrm{~h}$ with peak visitations occurring at $0800-0900,1200-1300$, and at 1400-1600 h during the day. The earliest visit time was at $0624 \mathrm{~h}$ (sunrise$0615 \mathrm{~h}$ ) and the last visit ended at $1814 \mathrm{~h}$ (sunset$1830 \mathrm{~h}$ ), both at separate fish-baited stations. There were no visitations recorded during the night. Based on first encounter of bait, the mean percent stations visited did not differ $(\mathrm{F}=0.93, \mathrm{df}=4, p=0.463$ ) among food baits (Fig. 1); however, visitations increased on days 2 and 3 compared to day 1 $(\mathrm{F}=4.20, \mathrm{df}=2, p=0.025)$, as new mongooses discovered the food baits. On day 1, mongooses visited $21.8 \%$ (egg), $27.3 \%$ (fish), $40.0 \%$ (beef), $40.0 \%$ (hot dog) and $30.0 \%$ (coconut) of the respective food bait stations. Visitation rates increased on exposure day 2 for egg $(41.7 \%)$ and fish $(50.0 \%)$ stations and slightly decreased for egg (33.3\%). After 3 days visitation of fish had increased to $55.0 \%$. Overall, female mongooses visited more stations than males $(\mathrm{F}=11.26$, df $=1, p=0.002)$. Unmarked immigrant mongooses, feral pigs, cats or rats partially or completely consumed bait at $<5 \%$ of stations exposed over the 1-3 day bait exposure period. Multiple visits to a single bait station by individual mongooses during a single day were common, as were multiple visits to multiple bait stations.

In addition to the percentage of bait stations visited, we examined the number of different mongooses visiting the different food baits by exposure day. The number of new mongooses visiting stations was similar ( $\mathrm{F}=1.10, \mathrm{df}=4, p=0.378)$ among the five baits evaluated. New mongoose visitors were higher $(\mathrm{F}=7.04, \mathrm{df}=2, p=0.003)$ on day $2(\mathrm{n}=2.9)$ and day $3(n=2.7)$ than for the first day $(n=1.3)$ of exposure. More different female $(\mathrm{n}=2.3)$ mongooses visited bait stations than males $(\mathrm{n}=1.3)(\mathrm{F}=8.30$, $\mathrm{df}=1, p=0.007)$. The mean percent of total stations revisited by mongooses on subsequent exposure days was 85.7 and $51.0 \%$ for egg and fish baited stations respectively. Re-visitation rates to egg stations were consistent for days 1-3 and increased or remained the same on day 2 and decreased on day 3 for fish-baited stations. The other baits were exposed for only 1 day in the field.

Mean travel distances (from day prior to bait exposure to first bait encounter) of radio-tagged only mongooses by gender are summarized in Table 2 . Overall bait discovery distances to coconut (mean = $345.6 \mathrm{~m}$, range $=157.5-482.1 \mathrm{~m})$, fish $\quad($ mean $=$ $302.7 \mathrm{~m}, \quad$ range $=134.5-620.7 \mathrm{~m})$, egg $\quad($ mean $=$ $194.6 \mathrm{~m}$, range $=34.8-467.5 \mathrm{~m})$, beef $($ mean $=$ $173.6 \mathrm{~m}$, range $=78.6-276.5 \mathrm{~m})$, and hot dog $($ mean $=121.4 \mathrm{~m}$, range $=28.8-214.1 \mathrm{~m})$ were similar $(\mathrm{F}=1.75$, $\mathrm{df}=4, p=0.170)$. A single male mongoose traveled $620.7 \mathrm{~m}$ from its original location prior to bait deployment to a fish-baited station the following morning. Male mongooses $(382.4 \mathrm{~m})$ traveled further $(\mathrm{F}=14.12$, $\mathrm{df}=1, p=0.009)$ to baits than females $(201.1 \mathrm{~m})$, especially to fish (mean = $403.8 \mathrm{~m}$ ) and egg $($ mean $=328.8 \mathrm{~m}$ ) bait stations as 


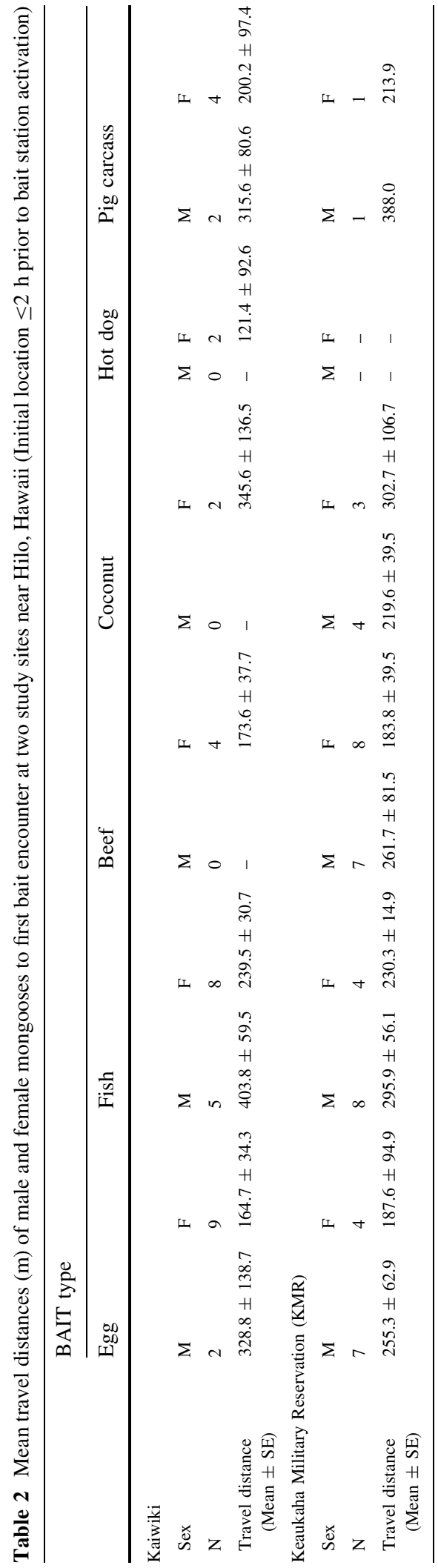

compared to females (fish $=239.5 \mathrm{~m}$, egg $=164.7 \mathrm{~m}$ ). The absence of visits to beef, hot dog or coconut by male mongooses precluded examination of gender differences in travel distance for those bait types.

The previous day's animal location $<30 \mathrm{~h}$ prior to bait exposure was used to compare bait discovery times (Table 3). Mongooses discovered the test food baits as early as $4 \mathrm{~h}$ after bait deployment on the same day to upwards of $69.5 \mathrm{~h}$ after the baits were deployed. Discovery times were not different $(\mathrm{F}=0.50, \mathrm{df}=4$, $p=0.738$ ) between the various food baits. Mean elapsed time to baits were $22.5 \mathrm{~h}$ (range $=$ 3.2-24.7 h) for coconut, followed by hot dog (mean $=$ $22.9 \mathrm{~h}$, range $=19.0-26.9 \mathrm{~h})$, egg $($ mean $=24.1 \mathrm{~h}$, range $=18.8-28.4 \mathrm{~h})$, fish $\quad($ mean $=25.0 \mathrm{~h}$, range $=15.0-28.5 \mathrm{~h}$ ), and beef (mean $=25.9 \mathrm{~h}$, range $=23.6-26.3 \mathrm{~h}$ ). There were no differences $(\mathrm{F}=1.13 \mathrm{df}=1, p=0.298)$ in discovery times by male $(28.7 \mathrm{~h})$ or female $(24.1 \mathrm{~h})$ mongooses. Since mongooses normally are inactive 10-12 h during the night, actual foraging discovery times would likely be considerably less than reported here.

Mongooses spent more time at beef $($ mean $=$ $36.0 \mathrm{~min}, \quad$ range $=1.0-75.0 \mathrm{~min}$ ) than coconut $($ mean $=10.0 \mathrm{~min}$, range $=1.0-17.0 \mathrm{~min})$ or egg $($ mean $=13.0 \mathrm{~min}$, range $=1.0-44.0 \mathrm{~min})$ stations $(\mathrm{F}=3.02, \mathrm{df}=4, p=0.026)$. Mean visitation times were $28.0 \mathrm{~min}$ (range $=1.0-89.0 \mathrm{~min}$ ) for fish and $19.1 \mathrm{~min}$ for hotdog $($ range $=1.0-40.0 \mathrm{~min})$ (Fig. 3a). There were no differences in time spent at stations by males or females $(\mathrm{F}=0.02, \mathrm{df}=1$, $p=0.877$ ). The physical (texture) and chemical (olfactory) properties of each bait type may have been a factor in the ease or difficulty in feeding on the bait and the time mongooses spent at the various food baits. Since all baits were secured in netting and attached to the bait station, in only a few instances were mongooses able to completely remove the bait and consume it offsite. It could not be determined from the datalogger data what proportion of the detections were in investigative behavior (inside the station) or in actual removal and consumption of the bait. All baits were generally completely removed from the stations when checked the next day and in a few instances small pieces of uneaten bait remained. In the few cases $(<5)$ where mongooses were detected at bait stations but the bait was untouched, that record was not included in the visitation summaries. 


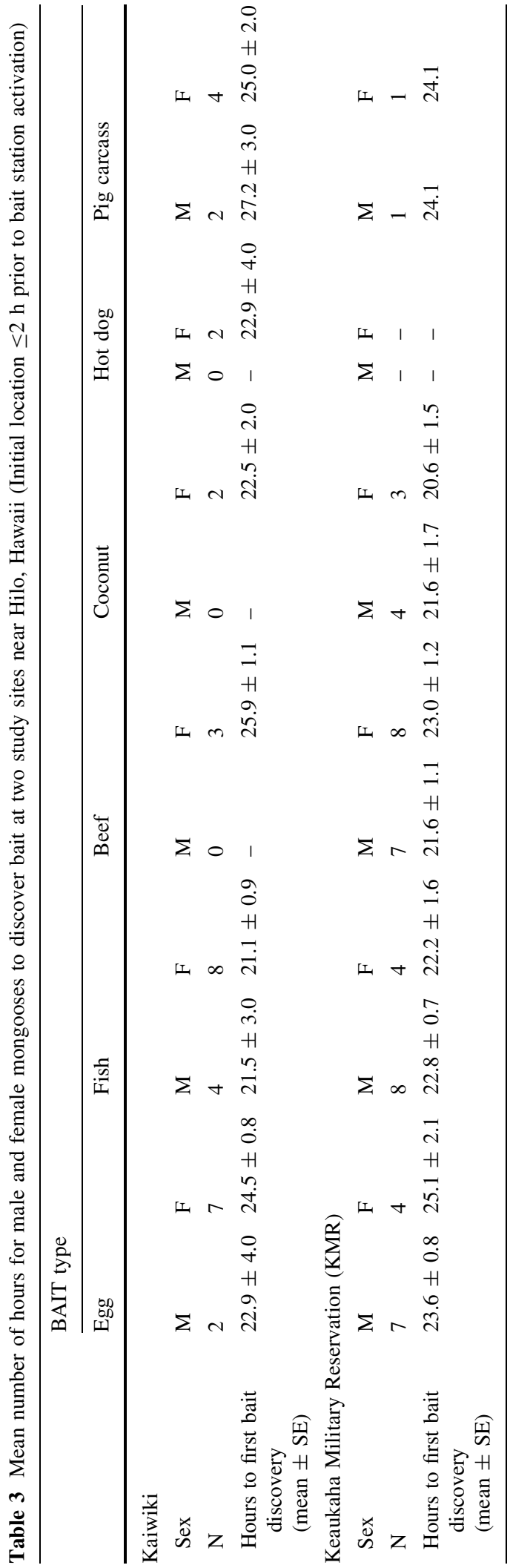

\section{Keaukaha Military Reservation}

We compared visitation to four food baits (fish, beef, egg, and coconut) by 29 marked mongooses ( $71 \%$ of those marked). Visitation was monitored during a 2-day exposure period over seven separate bait exposure sessions (11 December 2007-19 February 2008) in a total of 220 bait stations. Processed hotdog was not evaluated at this location due to its high incidence of invertebrate (ants, slugs, earwigs) infestation and resultant reduced bait availability observed after the first test period. Mongooses visited $37.5 \%$ (egg), $31.2 \%$ (fish), $31.2 \%$ (beef), and $43.7 \%$ (coconut) of the respective bait stations on the first day of exposure (Fig. 3). Percent visitation rates on day 2 increased for beef $(53.1 \%)$ and fish $(37.5 \%)$ and remained the same for egg and coconut (Fig. 3). Visitations increased for fish $(46.8 \%)$, decreased slightly for beef and coconut and remained the same for egg stations on the third day of exposure (Fig. 3). However, the percentage of stations visited (first discovery) by mongooses were not significantly different among food baits $(F=0.40$, $\mathrm{df}=3, p=0.756)$ or exposure days $(\mathrm{F}=1.26$, $\mathrm{df}=2, p=0.308)$. Visits to the various food baits were higher $(\mathrm{F}=6.90, \mathrm{df}=1, p=0.017)$ for female than male mongooses.

Mongooses were detected at the baits between 0600-1800 h with the majority of visitations occurring fairly evenly between $0800-1700 \mathrm{~h}$. Visitation peaks during the day were not as evident as at the Kaiwiki site. The earliest visit occurred at $0653 \mathrm{~h}$ and the last visit ended at $1806 \mathrm{~h}$. This diurnal activity period was slightly shorter at KMR (DecemberFebruary) than recorded at the Kaiwiki site (MarchJune) in response to shorter daylight hours.

Numerous visual sightings, vocalizations, and signs (diggings, feces, refugia dens) of feral pigs were noted in the KMR study site during the course of the study. Nine fish and four coconut bait stations were disturbed, destroyed or datalogging capabilities rendered inoperable by pigs. Salvaged mongoose visitation data recovered from these stations show that the disturbance by pigs occurred at night.

The number of new (different) mongoose visitors were similar $(\mathrm{F}=1.10$, df $=3, p=0.378)$ for the various food baits. However, unique mongoose visitations were higher $(\mathrm{F}=7.04, \mathrm{df}=2, p=0.003)$ on day $2(\mathrm{n}=2.9)$ and day $3(\mathrm{n}=2.7)$ as compared to the first day $(\mathrm{n}=1.3)$ of bait exposure. New female 
Fig. 3 Frequency of daily visitations (Days 1-3) to bait stations by male and female mongooses at 2 study sites
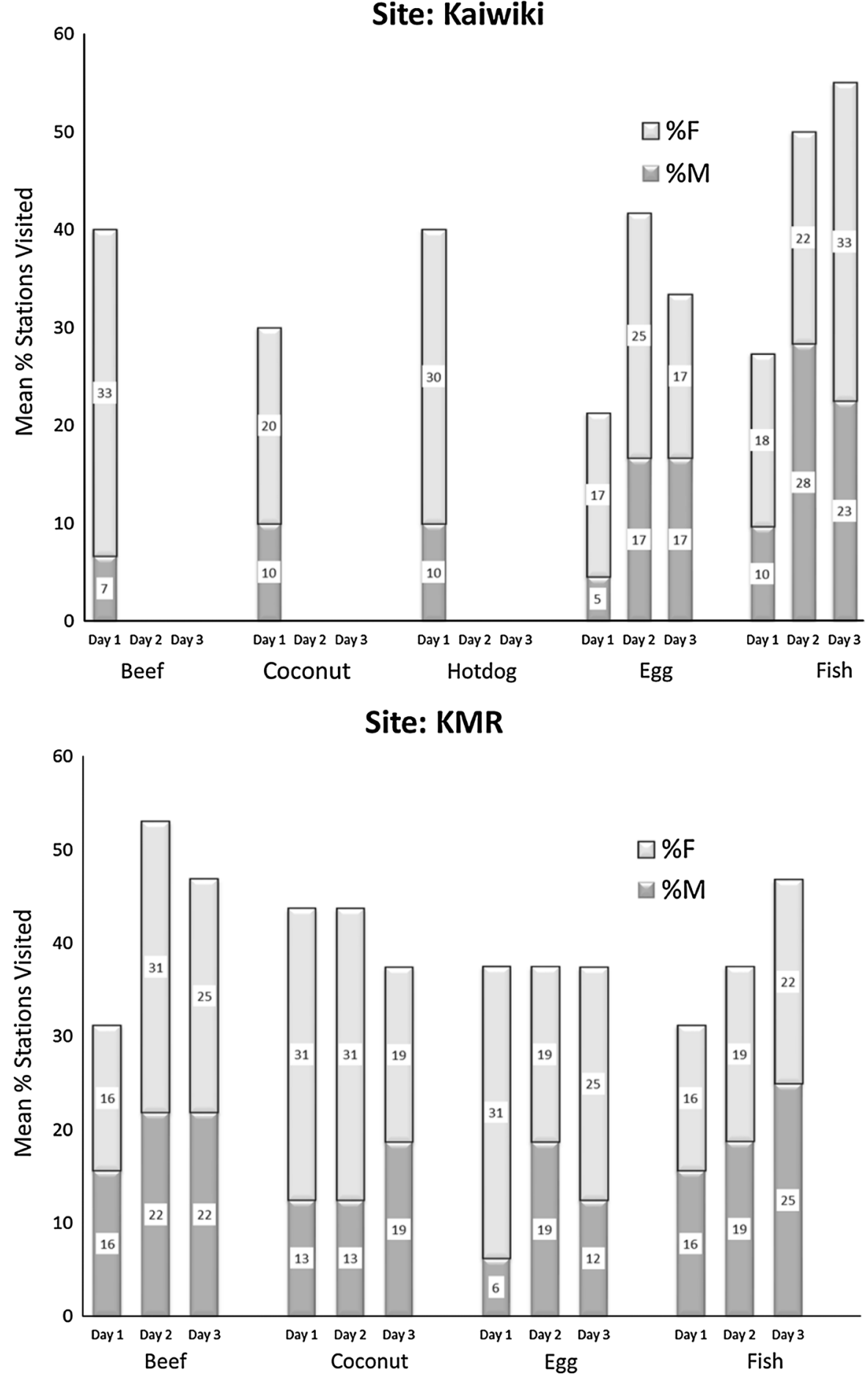

$(\mathrm{n}=2.3)$ mongooses visited more $(\mathrm{F}=8.30, \mathrm{df}=1$, $p=0.007)$ stations than male $(\mathrm{n}=1.3)$ mongooses. The mean percent of baited stations revisited on subsequent exposure days was highest for fish $(84.2 \%)$ followed by beef $(63.4 \%)$, egg $(59.5 \%)$ and coconut $(52.9 \%)$. Re-visitation rates to fish 
stations remained high for days $1-3$, and decreased on day 3 for coconut and egg stations.

Based on mean distance traveled to first bait encounter (day prior to bait exposure to first bait encounter), mongooses were equally $(\mathrm{F}=0.23$, $\mathrm{df}=3, \quad p=0.876)$ attracted to fish, $(274.0 \mathrm{~m}$, range $=125.4-598.1 \mathrm{~m})$, coconut $(255.2 \mathrm{~m}$, range $=$ $113.7-483.2 \mathrm{~m})$, egg $(23.7 \mathrm{~m}$, range $=44.1-544.7 \mathrm{~m})$, and beef $(220.1 \mathrm{~m}$, range $=19.4-542.1 \mathrm{~m})$ bait. The furthest travel distance $(598.1 \mathrm{~m})$ was by a male mongoose to a fish-baited station. Male $(264.0 \mathrm{~m})$ and female $(213.2 \mathrm{~m})$ attractive distances were similar $(\mathrm{F}=1.16, \mathrm{df}=1, p=0.288)$ for all baits (Table 2$)$. The dead pig carcass was visited by 2 mongooses (male/ female) with one male traveling $388.0 \mathrm{~m}$ from its previous day's location to the rotting carcass.

Mean bait discovery times were similar $(\mathrm{F}=1.75$, df $=1, p=0.174)$ for coconut $(21.2 \mathrm{~h}$, range = 17.1-24.8 h), egg (24.2 h, range $=19.7-28.5 \mathrm{~h})$, fish $(22.6 \mathrm{~h}$, range $=19.8-26.7 \mathrm{~h})$, and beef $(22.3 \mathrm{~h}$, range $=17.5-27.0 \mathrm{~h}$ ). Time to discover food baits was similar $(\mathrm{F}=0.19, \mathrm{df}=2, p=0.667)$ for male $(22.5 \mathrm{~h})$ and female $(22.9 \mathrm{~h})$ mongooses (Table 3$)$.

Upon initial bait discovery, mongooses spent more time $(\mathrm{F}=4.68, \mathrm{df}=3, p=0.004)$ at fish-baited stations $\quad($ mean $=20.7 \mathrm{~min}, \quad$ range $=1.0-87 \mathrm{~min})$ than at beef $($ mean $=12.0 \mathrm{~min}$, range $=1.0-54$ $\mathrm{min}), \quad$ egg $\quad($ mean $=7.54 \mathrm{~min}, \quad$ range $=1.0-41.0$ $\mathrm{min}$ ), or coconut stations (mean $=5.0 \mathrm{~min}$, range $=1.0-32.0 \mathrm{~min})$. Time at station was similar $(\mathrm{F}=0.44$, df $=1, p=0.509)$ for male and female mongooses.

\section{Site comparisons}

Mean whole body weights of mongooses captured at Kaiwiki $(504.8 \mathrm{~g})$ were greater $(\mathrm{F}=9.83, \mathrm{df}=1$, $p=0.003)$ than those at KMR (435.2 g). Mongoose home ranges $(\mathrm{F}=2.12, \mathrm{df}=1, p=0.156)$ and mean daily travel distance $(\mathrm{F}=0.13, \mathrm{df}=1, p=0.725)$ were similar between the 2 study sites. Visitations ( $\%$ stations visited) were similar $(\mathrm{F}=1.31, \mathrm{df}=1$, $p=0.257)$ between sites and there were no significant site-bait preference differences $(\mathrm{F}=0.91, \mathrm{df}=3$, $p=0.469$ ). Attractive distances of the various food baits were similar between study sites $(\mathrm{F}=0.01$, df $=1, p=0.056)$ as well as interactions between sites and bait type $(\mathrm{F}=0.50, \mathrm{df}=3, p=0.683$ ).

\section{Discussion}

Female mongoose captures predominated over males at both Kaiwiki (0.44 m:f sex ratio) and KMR (0.23). The high proportion of female captures is atypical of trapping studies conducted in Hawaii (Tomich 1979; Hays 2000). Coblentz and Coblentz (1985) also reported capturing twice as many females as males in a trap and removal study during October and November on St. John, US Virgin Islands; however, this was reported as an isolated and unusual occurrence. The reason for the skewed, female-biased sex ratio in the current study is unknown; however, we believed that this was not the result of sexual bias in trappability. Trapping conducted at Kaiwiki and near the KMR site in May 2004 using the same trap bait (coconut) reflected the normal male to female sex ratio of 1.29 and 1.00 respectively (Pitt and Sugihara 2008). Male mongooses may have dispersed further away from the study site or experienced higher than normal mortality prior to the study period. In addition, the high number of unmated females captured indicates a high proportion of newly dispersing female mongooses following the November-September breeding season for mongooses in Hawaii (Hays 2000).

Mongooses in this study foraged over a larger area (6.0-70.2 ha) than reported by other researchers in Hawaii and elsewhere. Hays and Conant (2007) reported home ranges of 8.2-25.7 ha during the breeding season and 1.2-3.3 ha during the nonbreeding season on the island of Oahu, Hawaii. Other investigators have reported home ranges of 3.9-19.4 ha in Puerto Rico (Quinn and Whisson 2005), 5.7-8.5 ha in Grenada (Nellis and Everard 1983), 22-39 ha in Fiji (Gorman 1979), and <5.0 ha in Amami, Japan (Abe 2008, pers. comm.). Extended home ranges of 25-100 ha were reported by Roy et al. (2002) in Mauritius and a toxicant baiting study by Keith et al. (1990) indicated average ranges of 8-191 ha at a lowland lava field on the island of Hawaii. The less productive lava habitat at this latter site may require greater foraging area and corresponding home range size. As in our study, all these investigators found extensive overlapping home ranges among individual mongooses, regardless of sex. A favorable habitat with abundant food resources and shelter (natural cavities and burrows), the apparent absence of defended territories and a complex social 
structure may permit the broad overlap of individual ranges by mongooses (Tomich 1969).

Male mongooses typically ranged (home range) over a larger area than females and also traversed greater distance within a $24-30 \mathrm{~h}$ period. Daily travel distances did not differ during the period before or after test baits were deployed at the Kaiwiki location but increased post-bait exposure at KMR. This may have been due to the higher visitation rates to all baits at the latter site. Attractiveness to novel food baits evaluated in this study may have been an artifact of available food resources at each study site. Although food resource availability was not quantified at either site, the more heavily vegetated Kaiwiki location probably supported more vegetation (fruits) and invertebrate resources which are commonly consumed by mongooses (Gorman 1975).

Mongooses were active over a longer period during the day in this study as compared to other investigations (Pimentel 1955; Nellis and Everard 1983; Quinn and Whisson 2005). Quinn and Whisson (2005) found that mongooses in Puerto Rico's Caribbean National Forest (now known as El Yunque National Forest) were most active from 1000 to $1600 \mathrm{~h}$ whereas the majority of mongooses in our study were detected at bait stations from 0800 to $1600 \mathrm{~h}$. We did not find significant periods of inactivity or peaks in mongoose activity during the day as was reported by Quinn and Whisson (2005).

We recorded population density estimates of 0.72 and 1.88/ha for the Kaiwiki and KMR sites, respectively. Previous field station trapping records at Kaiwiki and in areas bordering KMR during the fall and summer periods indicate higher capture rates than recorded in the current study. Seaman (1952) reported densities of up to 24.7/ha at some anthropogenic foodrich locations in Hawaii. Mongoose densities at our two study sites were higher than those estimated by Quinn and Whisson (2005) in Puerto Rico (0.19-0.57/ ha) and slightly lower than 2.6-6.4/ha found in Jamaica (Hoagland et al. 1989). However, caution must be exercised when interpreting population density estimates due to differing models and programs used. In addition, mongoose populations in Hawaii fluctuate greatly from year to year and between seasons (Pearson and Baldwin 1953; Tomich 1986).

All baits were considered novel foods at both study sites. Although live traps were baited with coconut to initially trap mongooses for identification (microchips, transmitters) and release, we feel that the extended period between trapping and field test food exposure (4-5 weeks) would not have allowed preconditioning of mongooses toward preference for the coconut trap bait.

Beef, hotdog and fish-baited stations elicited the highest initial (Day 1) visitation rate (percent stations visited) among the 5 food baits tested at Kaiwiki (40.0, 40.0 and $27.3 \%$ respectively). The absence of male mongoose visits to egg, hotdog and coconut baits at this site was unexpected and the reasons were unknown. At KMR beef, fish, egg, and coconut-baited stations accounted for 31.2, 31.2, 37.5 and $43.7 \%$ of visitations on the first bait exposure day. Linhart et al. (1993) reported a high proportion of egg-flavored and fish-flavored baits were taken on the day of placement. Creekmore et al. (1994) also found high acceptance of fishmeal-flavored polyurethane or polymer baits. Visitations to fish stations increased on subsequent exposure days (Day 2 and 3) and decreased or remained the same for eggs. These results are similar to trends observed in a previous study (Pitt and Sugihara 2008), suggesting that olfactory cues (fish) may be luring mongooses from afar on Day 2; whereas, mongooses were attracted visually to eggs. All food baits were attractive to mongooses at the KMR site and equally preferred on Days 1 and 2. The lower resource productivity at this site may explain the increased attractiveness of the novel food baits. Repeat visits were generally highest to fish-, beef- and eggbaited stations as compared to the other baits at both locations and increased on each subsequent exposure day. This indicates that individuals were spending more time within a familiar "food-rich" location than they normally would have, suggesting learned fidelity at a food source site.

Overall, preferences (\% stations visited) for the test food baits were higher for female mongooses; however, males were attracted from a greater distance to fish, beef, and egg baits. Male mongooses traveled upwards of $620 \mathrm{~m}$ to selected fish-baited stations. We exposed baits for a maximum of 3 days in this study and the high visitation and bait take did not allow for adequate evaluation of bait longevity. A majority of the bait stations had to be replenished with fresh baits over the short exposure period. Olfactory cues may be enhanced from decomposing baits exposed longer in the field as occurred with the unplanned discovery of the dead pig carcasses by mongooses at both locations. One male mongoose had traveled $743 \mathrm{~m}$ to the pig 
carcass from its previous day's location. Kami (1964) found scavenger beetles found in cattle dung and decaying carrion to be important food resources for mongooses.

We estimated bait discovery times by the time interval between the mongoose's prior day (pre-bait exposure) locations and the time it was detected at the bait station. Although a few visits occurred within $4 \mathrm{~h}$ the same day after baits were placed in the field, the majority of visitations occurred the following day. Some mongooses may have started moving towards baits the previous afternoon before seeking refugia due to darkness and continued traveling towards the bait source the following day. Actual discovery times include the $10-11 \mathrm{~h}$ of normal mongoose inactivity (1900-0600 h) and may be significantly less for some of the preferred baits (fish, beef, coconut).

The bait structure may have determined the time mongooses spent investigating and feeding at the bait stations upon initial discovery. Baits were enclosed in plastic mesh netting and secured to each station to prevent removal and maximize detection of implanted microchips by the automatic readers. That mongooses spent more time at fish-baited stations and least at egg or coconut stations may be due to the ease or difficulty of retrieving and consuming the baits. We assumed that the first mongoose visitor probably consumed most or all of the baits and spent the most time at the station; however, some stations did record similar or greater visit times by subsequent mongoose visitors. The status of baits in the station between checks could not be determined by the testing protocols and equipment used.

Local bait availability, field weatherability and longevity, ease of preparation and use, attractiveness to non-target invertebrates (ants, slugs, earwigs), and cost are factors that may determine final bait selection in different habitats and operational control situations. Coconut bait is readily available in Hawaii, is easy to prepare, store, and use; it maintains its palatability under extreme weather conditions. The previously frozen mackerel fish used in this study was the most expensive of the baits tested and may be only seasonally available. While whole chicken egg was also attractive to mongooses its cost and fragility in transport and handling may limit its large scale use in the field. Beef scraps were obtained at no cost from local meat vendors and processed foods such as hot dogs quickly attracted invertebrates and other non- target feeders that quickly reduced the quality and quantity of bait available for target mongooses.

Management implications

The results of this field study, together with screening trials conducted previously (Pitt and Sugihara 2008), provide current information on mongoose foraging ecology in Hawaii and response to different food baits. This information can be used to develop effective management strategies in detecting and trapping mongooses in newly established areas as well as reducing populations in sensitive native bird nesting habitats. We found that a majority of mongooses in a given area can be trapped in a short period of time and in-migration of new individuals into established habitats is relatively slow.

Disturbed habitats and natural areas adjacent to human habitat and use, especially with abundant anthropogenic food resources, can support high populations of omnivorous mammals (Kami 1964; Gorman 1975; Fedriani et al. 2001; Quinn and Whisson 2005). We found mongooses could travel and forage over large areas but had a restricted normal area of use, usually around known food reserves. Based on the home ranges, daily travel distances, and extensive overlapping habitat use patterns among resident mongooses, greater trap or bait station spacing $(150-200 \mathrm{~m})$ than is currently used $(25-100 \mathrm{~m})$ operationally can be employed. Traps placed along habitat edges and transition zones, usually with easily accessible roads, can be effective in controlling mongooses from the interior of the site.

Mongooses readily investigated and consumed a variety of novel food baits evaluated in this study. Fish, beef, egg, and coconut were highly attractive baits that elicited multiple visitations to baited stations. Coconut chunks are easy to use in traps and a processed fish sausage formulation has been used successfully in Okinawa and Amami, Japan (Yamada 2002; Yamada and Sugimura 2004; Abe 2008) to trap mongooses. Our study suggests that maintaining fresh baits in traps may not be as critical a concern as believed by current control practitioners. Decomposing animal-based baits may be very effective in attracting mongooses from a distance; however, bait matrix integrity in traps and operator acceptance in handling rotten baits may be factors that determine its applicability and use. 
In areas co-occupied by native mammals that may be attracted to baited traps, the selection of mongoosespecific baits or excluding non-target captures is a major concern (Dilks et al. 1996). While this was not a concern in our study, coconut bait also attracted nonnative rats (Rattus rattus, $R$. exulans) and mice (Mus musculus); the fish and beef baits were frequently visited by feral pigs (Sus scrofa). Conservationists in Japan use live traps exclusively over the more effective kill traps in areas where two species of native rodents and mongooses co-occur (Abe 2008). The discovery of mongoose-specific bait is a primary objective of the Japanese investigators.

\section{Future research}

Few attempts at eradication of introduced mongooses from islands have been successful (Everard and Everard 1985; Yamada and Sugimura 2004; Abe 2008; Barun et al. 2011). Besides trapping, other techniques such as barriers (Ogura 2008) and diphacinone bait stations in Hawaii (Keith et al. 1990; Smith et al. 2000) have resulted in limited use or success. Fertility control, taste aversion, and other toxins such as para-aminopropiophenone (PAPP) (Savarie et al. 1983; Fisher and O'Connor 2007) warrant further research. Conspecifics' anal gland secretions, feces or urine play an important role in eliciting social interactions among individuals of many carnivore species (Howard et al. 2002) and could be exploited in attracting mongooses to traps.

Based on these results, we plan to evaluate the efficacy of two diphacinone rodenticide formulations approved for use in conservation areas in Hawaii and the Pacific. Diphacinone bait blocks in tamper-proof bait stations are currently registered to reduce rodent and mongoose populations to protect native species. However, the attractiveness of the wax bait substrate of this bait in areas of highly abundant and attractive alternate foods is questionable and needs further investigation. In addition, a fish-flavored pelleted formulation of diphacinone bait is registered for broadcast application to control rodents in remote native ecosystems and offshore islands in Hawaii. Mongooses could potentially find and consume enough pellets within their normal daily foraging area to be impacted based on the $\mathrm{LD}_{50}$ of diphacinone for mongoose, but no data are available on whether mongooses would be attracted to and consume these pellets.
Acknowledgments $\mathrm{We}$ are grateful for the support and assistance provided by the U. S. Fish and Wildlife Service, Pacific Islands Fish and Wildlife Office. Capture, handling and marking of mongooses was performed with approval of the National Wildlife Research Center's Institutional Animal Care and Use Committee February 25, 2005 under QA-1255. We thank Michael W. Fall and Catherine E. Swift for assistance with literature review and manuscript preparation. Special thanks to two anonymous reviewers for helpful and insightful comments on an earlier draft of this manuscript.

\section{References}

Abe S (2008) Current mongoose eradication efforts of two islands of Ryukyu Archipelago, Japan. Control Strategy for Invasive Alien Mammals (CSIAM) 2008 Symposium. Naha, Okinawa, Japan. 27 Oct-1 Nov 2008

Anonymous (2010) Predator damage management to protect avian wildlife in Hawaii. Final Environmental Assessment, U. S. Department of Agriculture. p 5

Baker JK, Russell CA (1979) Mongoose predation on a nesting nene. Elepaio 40:51-52

Baldwin PH, Schwartz CW, Schwartz ER (1952) Life history and economic status of the mongoose in Hawaii. J Mammal 33:335-356

Banko PC (1982) Productivity of wild and captive nene populations. Proc Hawaii Volcano Natl Park Nat Sci Conf 4:12-32

Banko PC (1992) Constraints on productivity of wild Nene or Hawaiian Geese Branta sandvicensis. Wildfowl 43:99-106

Barun A (2011) The small Indian mongoose (Herpestes auropunctatus) on Adriatic Islands: impact, evolution, and control. PhD dissertation, University of Tennessee, Knoxville

Barun A, Hanson CC, Campbell KJ, Simberloff D (2011) A review of small Indian mongoose management and eradications on Islands. In: Veitch CR, Clout MN, Towns DR (eds) Island invasives: eradication and management. IUCN, Gland, pp 17-25

Blanton JD, Meadows A, Murphy SM, Managan J, Hanlon CA, Faber M, Dietzschold B, Rupprecht CE (2006) Vaccination of small Indian mongoose (Herpestes javanicus) against rabies. J Wildl Dis 42:663-666

Bryan WA (1908) Some birds of Molokai. Occasional Papers, Bernice P. Bishop Museum 4(2):133-176

Coblentz BE, Coblentz BA (1985) Reproduction and the annual fat cycle of the mongoose on St. John, US Virgin Islands. J Mammal 66:560-563

Creekmore TE, Linhart SB, Corn JL, Whitney MD, Snyder BD, Nettles VF (1994) Field evaluation of baits and baiting strategies for delivering oral vaccine to mongooses in Antigua, West Indies. J Wildl Dis 30:497-505

Dilks P, O'Donnell CF, Elliott GP, Phillipson SM (1996) Effect of bait type, tunnel design and trap position on stoat control operations for conservation management. NZ J Zool 23:295-306

Eijzenga J (2004) Identifying key predators of endangered Hawaiian stilt chicks. Abstract presented at the 2004 Hawaii Conservation Conference, Honolulu, HI 
Espeut WB (1882) On the acclimatization of the Indian mongoose in Jamaica. P Zool Soc Lond 1882:712-714

Everard COR, Everard JD (1985) Mongoose rabies in Grenada. In: Bacon PJ (ed) Population dynamics of rabies in wildlife. Academic Press, London, pp 43-69

Fedriani JM, Fuller TK, Sauvajot RM (2001) Does availability of anthropogenic food enhance densities of omnivorous mammals? An example with coyotes in southern California. Ecography 24:325-331

Fisher P, O'Connor C (2007) Oral toxicity of p-aminopropiophenone to ferrets. Wildl Res 4:19-24

Giffin JG (1983) Movements, survival, reproductive success and habitat of Koloa on the island of Hawaii. Final report, Hawaii Division of Fish and Game, Pittman-Robertson Project No w-18-R-8, Job No R-III-H

Gorman ML (1975) The diet of feral Herpestes auropunctatus (Carnivora: Viverridae) in the Fijian Islands. J Zool 175:273-278

Gorman ML (1979) Dispersion and foraging in the small Indian mongoose relative to the evolution of social viverrids. J Zool 187:65-73

Hays WST (2000) Behavioral and population ecology of the small Indian mongoose [Herpestes javanicus (Geoffroy 1818)] in Hawaii. PhD dissertation, Univ Hawaii, Honolulu, HI

Hays WST, Conant S (2007) Biology and impacts of Pacific Island invasive species: a worldwide review of effects of the small Indian Mongoose, Herpestes javanicus (Carnivora: Herpestidae). Pac Sci 61(1):3-16

Hoagland DB, Horst GR, Kilpatrick CW (1989) Biogeography and population biology of the mongoose in the West Indies. In: Woods CA (ed) Biogeography of the West Indies. Sandhill Crane Press, Gainesville, pp 611-634

Hodges CSN, Nagata RJ (2001) Effects of predator control on the survival and breeding success of the endangered Hawaiian dark-rumped petrel. Stud Avian Biol 22:308-318

Howard ME, Zuercher GL, Gipson PS, Livingston TR (2002) Efficacy of feces as an attractant for mammalian carnivores. Southwest Nat 47(3):348-352

Kami HT (1964) Foods of the mongoose in the Hamakua District, Hawaii. Zoonoses Res 3(3):165-170

Keith JO, Hirata DN, Espy DL, Greiner S, Griffin D (1990) Field evaluation of $0.00025 \%$ diphacinone bait for mongoose control in Hawaii. USDA/APHIS/Denver Wildlife Research Center, Denver

Linhart SB, Creekmore TE, Corn JL, Whitney MD, Snyder BD, Nettles VF (1993) Evaluation of baits for oral rabies vaccination of mongooses: pilot field trials in Antigua, West Indies. J Wildl Dis 29:290-294

Nellis DW (1989) Herpestes auropunctatus. Mammal Species 342:1-6

Nellis DW, Everard COR (1983) The biology of the mongoose in the Caribbean. Studies on the fauna of Curacao and other Caribbean Islands. 64:1-162

Nellis DW, Small V (1983) Mongoose predation on sea turtle eggs and nests. Biotropica 15:159-160

Ogura G (2008) Development of a mongoose-proof fence and its adaptation for the southern limit of the Yanbaru forest region on Okinawa Island, Ryukyu Archipelago, Japan. Control Strategy for Invasive Alien Mammals (CSIAM)
2008 Symposium, Naha, Okinawa, Japan. 27 Oct-1 Nov 2008

Pearson OP, Baldwin PH (1953) Reproduction and age structure of a mongoose population in Hawaii. $\mathrm{J}$ Mammal 34:436-447

Pimentel D (1955) Biology of the Indian mongoose in Puerto Rico. J Mammal 36:62-68

Pitt WC, Sugihara RT (2008) Evaluation of selected natural and artificial attractants, lures, and bait substrates for attracting small Indian mongooses (Herpestes auropunctatus) to traps and activity stations in Hawaii. Hilo, Final report, USDA, APHIS, WS, NWRC

Quinn JH, Whisson DA (2005) The effects of anthropogenic food on the spatial behaviour of small Indian mongooses (Herpestes javanicus) in a subtropical rainforest. J Zool 267:339-350

Roy SS, Jones CG, Harris S (2002) An ecological basis for control of the mongoose Herpestes javanicus in Mauritius: is eradication possible? In: Veitch CR, Clout MN (eds) Turning the tide: the eradication of invasive species: IUCN. Gland, Switzerland and Cambridge, pp 266-273

Savarie PJ, Ping Pan H, Hayes DJ, Roberts JD, Dasch GL, Felton R, Schafer EW Jr (1983) Comparative acute oral toxicity of para-aminopropiophenone (PAPP) in mammals and birds. Bull Environ Contam Toxicol 30:122-126

Seaman GA (1952) The mongoose and Caribbean wildlife. Trans N Am Wildl Conf 17:188-197

Seaman GA, Randall JE (1962) The mongoose as a predator in the Virgin Islands. J Mammal 43:544-546

Smith DG, Polhemus JT, Van der Werf EA (2000) Efficacy of fish-flavored diphacinone bait blocks for controlling small Indian mongooses (Herpestes auropunctatus) populations in Hawaii. Elepaio 60(6):47-51

Stone CP, Keith JO (1987) Control of feral ungulates and small mammals in Hawaii's national parks: research and management strategies. In: Richards CGJ, Ku TY (eds) Control of mammal pests. Taylor and Francis, London, pp 277-287

Stone CP, Dusek M, Aeder M (1994) Use of an anticoagulant to control mongooses in Nene breeding habitat. Elepaio 54(12):73-78

Tomich PQ (1969) Movement patterns of the mongoose in Hawaii. J Wildl Manag 33(3):576-584

Tomich PQ (1979) Studies of leptospirosis in natural host populations. Small mammals of Waipio Valley, Island of Hawaii. Pac Sci 33:257-279

Tomich PQ (1986) Mammals in Hawaii: a synopsis and notational bibliography. In: Bernice P. Bishop Museum 2nd ed, Special Pub 57, Bishop Museum Press, Honolulu, HI

Vilella FJ (1998) Biology of the mongoose (Herpestes javanicus) in a rain forest of Puerto Rico. Biotropica 30:120-125

Watari Y, Takatsuki S, Miyashita T (2008) Effects of exotic mongoose (Herpestes javanicus) on the native fauna of Amami-Oshima Island, southern Japan, estimated by distribution patterns along the historical gradient of mongoose invasion. Biol Invasions 10:7-17

White GC, Anderson DR, Burnham KP, Otis DL (1982) Capture-recapture and removal methods for sampling closed populations. Los Alamos National Laboratory, Los Alamos

Yamada F (2002) Impacts and control of introduced small Indian mongoose on Amami Island, Japan. In: Veitch CR, Clout MN (eds) Turning the tide: the eradication of 
invasive species. IUCN, Gland, Switzerland and Cambridge, UK, pp 389-392

Yamada F, Sugimura K (2004) Negative impact of an invasive small Indian mongoose, Herpestes javanicus on native wildlife species and evaluation of a control project in Amami-Ohshima and Okinawa Islands, Japan. Glob Environ Res 8(2):117-124 